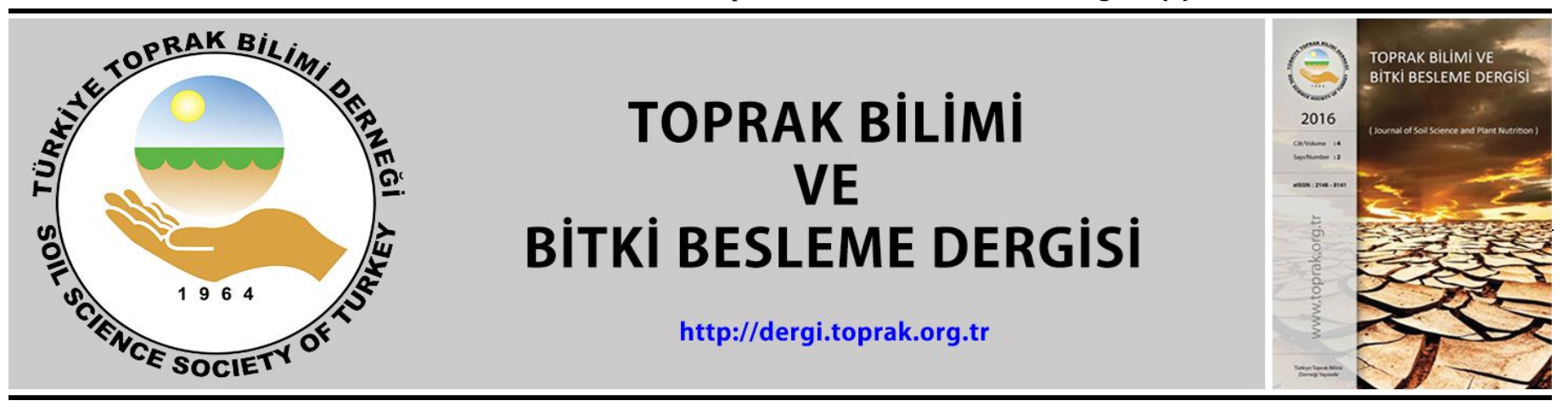

\title{
Toprak sıcaklığının tahmininde ısı taşınım denklemi ve pedotransfer fonksiyonun karşılaştırılması
}

\section{Coşkun Gülser *, İmanverdi Ekberli}

Ondokuz Mayıs Üniversitesi, Ziraat Fakültesi, Toprak Bilimi ve Bitki Besleme Bölümü, Samsun

\section{Özet}

Bu çalışmanın amacı toprak profili boyunca sıcaklık değerlerinin tahmininde kullanılan, ısı taşınım denkleminin çözümünden elde edilen cosinusoidal harmonik fonksiyon (Tcos) ile pedotransfer (Tped) fonksiyonu karşılaștırmaktır. Deneysel olarak kil bünyeli bir toprağın 0-70 cm profil derinliğinde günün farklı saatlerinde yapılan sıcaklık ölçüm değerleri yüzey ve yüzeye yakın toprak katmanlarında $(<30 \mathrm{~cm})$ daha çok salınım gösterirken, toprağın daha derin katmanlarda $(>30 \mathrm{~cm})$ bu salınımın daha az olduğu belirlenmiștir. Yüzey toprak katmanında $(10 \mathrm{~cm})$ Tcos eșitliği ile hesaplanan değerler ölçülen toprak sıcaklık değerleri ile daha iyi uyum gösterirken, toprağın alt katmanlarında ölçülen sıcaklık değerleri Tped fonksiyonu ile hesaplanan değerler ile daha iyi uyum göstermiştir. Toprak profili boyunca ölçülen sıcaklık değerleri ile Tped fonksiyonuyla hesaplanan değerler daha yüksek $\mathrm{R}^{2}\left(0,766^{* *}\right)$ ve daha düşük HKOK $(0,99)$ verirken, Tcos ile hesaplanan değerler daha düşük $\mathrm{R}^{2}\left(0,672^{* *}\right)$ ve daha yüksek HKOK $(1.20)$ vermiştir. Amplütüt, ısı yayınımı, gecikme zamanı ve sönme derinliği gibi bazı parametrelere sahip Tcos eşitliği ile karşılaştırıldığında, pedotransfer fonksiyonunun avantajı sadece yüzey toprak sıcaklığını kullanarak verilen sınır koşulları içerisinde toprağın herhangi bir derinliğinde toprak sıcaklığının tahmin edilebilmesidir. Toprak sıcaklığının tahmininde kullanılabilecek pedotransfer fonksiyonların farklı toprak ve atmosfer sınır koşulları için geliştirilmesi, bu fonksiyonların kullanımlarındaki güvenirlik ve hassasiyetlerini de artıracaktır.

Anahtar Kelimeler: Toprak sıcaklığı, ısı akıș denklemi, pedotransfer fonksiyon, toprak derinliği.

\section{Comparison of heat flow equation and pedotransfer function in prediction of soil temperature}

\section{Abstract}

The objective of this study is to compare the cosinusoidal harmonic function (Tcos) obtained from the solution of heat transfer equation and the pedotransfer (Tped) function which are used in prediction of temperature values along the soil profile. Experimentally, while daily temperature measurement values of $0-70 \mathrm{~cm}$ a clay soil profile depth at different times showed more fluctuations at the surface and near the surface soil layers $(<30 \mathrm{~cm})$, it showed less fluctuations at deeper soil layers $(>30 \mathrm{~cm})$. The values calculated by Tcos equation fitted very well with the measured soil temperature values at the surface soil layer $(10 \mathrm{~cm})$, while the temperature values measured at the lower soil layers showed better agreement with the values calculated by Tped function. The values calculated with Tped function gave higher $\mathrm{R}^{2}\left(0.766^{* *}\right)$ and lower HKOK $(0.99)$ with the temperature values measured through soil profile while the values calculated with Tcos gave lower $\mathrm{R}^{2}\left(0.672^{* *}\right)$ and higher HKOK (1.20). When comparing with the Tcos equation having some parameters such as; amplitude, heat diffusivity, retardation time and damping depth, the advantage of the pedotransfer function is that the soil temperature can be predicted at any soil depth using just the surface soil temperature.The development of pedotransfer functions for different soil and atmospheric boundary conditions will increase their reliability and sensitivity for estimating soil temperature.

Keywords: Soil temperature, heat flow equation, pedotransfer function, soil depth

(C) 2019 Türkiye Toprak Bilimi Derneği. Her Hakkı Saklıdır

\section{Giriş}

Günümüzde yaşanan küresel iklim değişikleri diğer çevresel olaylarla beraber, topraktaki sıcaklık değişimine, dolayısıyla toprak süreçlerinin gelişimine önemli düzeyde erki yapmaktadır. Toprakta sıcaklık değişiminin değerlendirilmesi, toprakların muhafazası ve yönetimlerinin belirlenmesinde gerekli aşamalardan birisidir. Toprak yüzeyinde ve alt katmanlarındaki sıcaklık değişimleri ısı alanının oluşumuna ve toprağın termofiziksel özelliklerinin değişimine neden olmaktadır. Toprak sıcaklığının farklı ortamlarda belirlenmesinde ve tahmin edilmesinde, birçok araştırmacı tarafından (Haverd ve ark., 2007; Ekberli ve ark.,

\footnotetext{
* Sorumlu yazar:

Tel. : : $\quad 03623121919$

E-posta : cgulser@omu.edu.tr
}

Geliş Tarihi

Kabul Tarihi
12 Ocak 2019

25 Kasım 2019
e-ISSN

2146-8141

$10.33409 /$ tbbbd.668902 
2015; Ekberli ve Gülser, 2014; 2015; Gülser ve ark., 2018; Xing ve ark., 2018) deneysel ve teorik yöntemler kullanılmıştır. Toprak sıcaklığı, bitki gelişiminde önemli olan ısı akışı ve enerji bilançosu faktörlerinin oluşumunda da temel bir fonksiyondur (Chen ve ark., 1999; Shao ve ark., 2014). Toprak sıcaklığı, toprağın termofiziksel değişkeni olup, toprağın nem değişiminin düzenlenmesinde ve kontrolünde de önemli bir parametredir (Dong ve ark., 2015; Merlin ve ark., 2018). Yan ve ark. (2018) tarafından yapılan bir çalışmada, toprak sıcaklığı deneysel olarak belirlenmiş, yüzey toprak rölyefinin sıcaklığı önemli düzeyde etkilediği vurgulanmış ve antropojen faktörlerin toprağın $10 \mathrm{~cm}$ derinliğinde sıcaklık artışına neden olduğu gösterilmiştir. Türkiye'nin farklı bölgelerine ait toprak sıcaklığının teorik olarak incelenmesine ait bir çalışmada (Yener ve ark., 2017), toprağın 5, 10, 20, 50 ve $100 \mathrm{~cm}$ derinliklerine ait meteoroloji sıcaklık verileri kullanılmış; hava sıcaklığı ile katmanlardaki toprak sıcaklıkları arasında ilişki belirlenmiştir. Her bölge için farklı teorik modeller kullanarak, toprak katmanlarında sıcaklık değerleri tahmin edilmiştir.

Araştırmanın amacına bağlı olarak, toprak sıcaklığının zamana ve toprak derinliğine göre değişimi, ıSı iletkenliği denkleminin farklı sınır koşullarındaki çözümüne ve deneysel verilere dayanan pedotransfer modellere göre incelenmektedir. Hu ve ark. (2016), toprak sıcaklığının, toprağın termal özelliklerinin veya su akışının belirlenmesi için, sınır koşulu olarak Fourier serisini kullanarak isı iletkenlik denkleminin çözümünü geliştirmiş, sınır koşulunun harmonik (sinüsoidal) fonksiyonla ifadesi durumunda da çözümün uygulanabilirliğini göstermişlerdir. Sınır koşullarının harmonik ve Fourier serisi ile ifadesi durumunda elde edilen çözüme göre, toprağın $10 \mathrm{~cm}$ derinliğinde hesaplanan ve ölçülen değerler arasındaki tahminin standart hatasının, normalleștirilmiş standart hatanın ve mutlak hatanın sırasıyla 0.55; 9.26; 0.47 ve 0.16; 2.7; 0.11 olduğunu saptamışlardır. Toprakta ısı akışının belirlenmesine ait yeni bir yaklaşıma ait yapılan araştırmada (Wang ve Bou-Zeid, 2012), toprağın ısı iletkenliği denkleminin, yüzey toprak sıcaklığının değişimini ifade eden ve sinüsoidal fonksiyonla ifade olunan sınır koşuluna dayanan çözümü kullanılmıştır. Önerilen matematiksel yönteme göre hesaplanan sıcaklık değerleri kullanılarak, toprağın günlük yüzey ısı akışının haritalanmasının mümkün olabileceği vurgulanmıştır. Xu ve ark.(2018), çeşitli toprak ortamında su, tuz/azot değişimini, ısı taşınımını, bitki boyu ve verimini modellemek ve değerlendirmek için yapılan bir araştırmada, su buharı difizyonunun etkisi ihmal edilerek, bir boyutlu isı taşınımının ifadesinde konveksiyon-dispersiyon denklemi kullanılmıștır. Sulanan ve bitki yetiştirilen kumlu bir toprağın yüzeyinde ısı ve su taşınımı tahmininde, ısı iletkenliği denklemine dayanarak yapılan bir boyutlu sayısal model kullanılmış, modelin vejetasyon döneminde buğday bitkisini kök bölgesinde ısı ve sıcaklık değişiminin belirlenmesinde uygulanabilirliği gösterilmiștir (Ji ve ark., 2009). Munoz-Criollo ve ark. (2014), toprakta güneş enerjisinin depolanması ve korunmasına yönelik bir çalışmada, mevsimler arası ısı akışının modellenmesinde bir boyutlu homojen olmayan ısı iletkenliği denklemi kullanılmışlardır. Genel olarak, ısı iletkenliği denkleminin hidroloji, jeoloji, hidrodinamik, jeodinamik, elektrodinamik, nemli cisimlerde isı ve su transferine dayanan kurutma teorisi, yapı mühendisliği vb. alanlarda; ortamın enerji bilançosunun, radyasyon değişiminin, ısı ve su akışının, termofiziksel özelliklerinin değerlendirilmesinde; toprakta isı ve madde değișimi gibi fiziksel süreçlerin incelenmesinde geniş uygulamaları vardır (Kaltreider ve ark., 2015; Cho ve ark., 2017; Ekberli ve ark., 2017).

Pedotransfer fonksiyonlar (PTF), toprağın deneysel olarak belirlenen özellikleri arasındaki karşılıklı nicel etkilerinden yararlanılarak yapılmaktadır. İncelenen özellikler arasındaki neden-sonuç ilişkisini açıklamadan, araştırılan özelliğin fonksiyonel olarak bulunmasına yönelik olmaktadır. "PTF" terimi ilk olarak Bouma ve van Lanen (1987) tarafından kullanılmıştır. Daha sonraları, Bouma (1989) tarafından toprağın (pedo) temel özelliklerine ait bilgilere bağlı olarak, topraktaki su taşınımını (transfer) ifade eden fonksiyonel ilişkiler yapılmıştır. Günümüzde PTF terimi, toprak biliminin tüm alanlarında toprak özellikleri arasındaki ilişkilerin matematiksel ifadesinde geniş düzeyde kullanılmaktadır (Pachepsky ve Rawls, 2003; Donatelli ve ark., 2004; Pachepsky ve ark., 2006; Candemir ve Gülser, 2012; Evrendilek ve ark., 2012). PTF'lerin yapılmasında çoklu doğrusal regresyon, yapay sinir ağları, genetik programlama, karar ağacı analizi gibi çeşitli yöntemler kullanılmaktadır (Ghanbarian ve ark., 2017). Yapılan araştırmalar, PTF’lerin toprak özelliklerinin kuvvetini, karekökünü ve çarpımını kapsayan çoklu terimlerle ifadesinin, regresyon katsayısını, dolayısıyla tahminin önem düzeyini yükselttiğini göstermektedir (Donatelli ve ark., 2004; Gülser, 2004; Gülser ve ark., 2007; Evrendilek ve ark., 2012; Ekberli ve Dengiz, 2017). Regresyon modellerine dahil olan parametrelerin fazla olması (>20-30) modellerin uygulanabilirliğini zorlaştırmaktadır. Diğer modellerde olduğu gibi, PTF oluşumunda da, gerçek ortamdaki parametreler arasındaki ilişkilerin ve karşılıklı etkilerin detaylı matematiksel ifadesi mümkün değildir. Parametreler arasındaki fonksiyonel ilişkilerin belirlenmesinde, bazı sınırlamaların dahil edilmesi, regresyon modellerinin olumsuz yanıdır. 
Toprak sıcaklığı ile toprağın termo-fiziksel ve diğer özellikleri arasındaki matematiksel ilişkilerin belirlenmesi, termo pedo-transfer fonksiyonlar (TPTF) ile mümkündür. TPTF'lerin yapılmasında, toprak sıcaklığı ile önemli düzeyde karşılıklı etkide olan parametrelerin göz önüne alınması gerekmektedir. Singh ve ark. (2018) tarafından yapılan bir araştırmada, toprağın $5 \mathrm{~cm}, 10 \mathrm{~cm}, 20 \mathrm{~cm}$ derinliklerindeki sıcaklığın belirlenmesinde girdi parametreleri havanın maksimum ve minimum sıcaklıkları, buharlaşma bağıl nem, rüzgar hızı olan doğrusal regresyon denklemi (pedotransfer fonksiyon) kullanılmıştır. Türkiye'nin bazı bölgelerinde toprağın 0-5 cm katmanındaki sıcaklı̆̆ın ve havanın maksimum ve minimum sıcaklıklarının değişiminin değerlendirilmesinde de zamana (ay) bağlı 3. dereceden doğrusal regresyon denklemi uygulanmıştır (Evrendilek ve ark., 2012).

Bu çalışmanın amacı, toprak profili boyunca ısı taşınım denkleminin çözümünden elde edilen cosinusoidal harmonik fonksiyona ve pedotransfer fonksiyona göre hesaplanan toprak sıcaklıklarının nicel olarak değerlendirilmesi ve karşılaştırılmasıdır.

\section{Materyal ve Yöntem}

Araştırma Ondokuz Mayıs Üniversitesi Kampus Yerleşim sahası Ziraat Fakültesinin deneme alanında, 2x3m

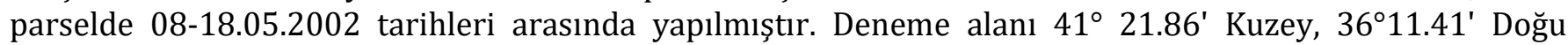
koordinatlarında, deniz seviyesinden 187 m yükseklikte yer almaktadır. Deneme alnın toprağının kil, silt ve kum içerikleri hidrometre yöntemine göre (Demiralay, 1993), organik madde (OM) kapsamları modifiye Walkley-Black yöntemine göre saptanmıștır (Kacar, 1994). Toprakların elektriksel iletkenlik değerleri (EC25.4ํㅡ) 1:1 toprak:su süspansiyonunda, $\mathrm{CaCO}_{3}$ miktarı "Scheibler Kalsimetresi" kullanılarak hacim esasına göre belirlenmiştir (Hızalan ve Ünal, 1966).

Toprak sıcaklığı günlük olarak 9:00, 12:00, 16:00, 19:00 saatlerinde civalı cam termometre ile 0, 10, 20, 30, 40, 50, 60 ve $70 \mathrm{~cm}$ katmanları için ölçülmüştür (Sterling and Jaskson, 1986).

Arazide ölçülen toprak sıcaklık değerlerinden yararlanılarak, toprağın $x_{i}-x_{i+1}$ katmanındaki ısısal yayınım katsayısı $\left(\mathrm{cm}^{2} \mathrm{sn}^{-1}\right)$

$$
a=\frac{\omega\left(x_{i}-x_{i+1}\right)^{2}}{2\left(\ln \left(A_{i} / A_{i+1}\right)^{2}\right.}(i=\overline{1, n})
$$

İfadesi belirlenerek, teorik toprak sıcaklıklarının belirlenmesinde toprağın ısı taşınımı (2) denkleminin (3) koşulunu sağlayan (4) çözümü kullanılarak toprak sıcaklıkları her bir toprak katmanı için hesaplanmıştır.

$$
\begin{array}{r}
\frac{\partial T}{\partial t}=a \frac{\partial^{2} T}{\partial x^{2}}(0 \leq x<\infty, t>-\infty) \\
T(0, t)=A \cos \omega t \\
T(x, t)=T_{O(x)}+A e^{-\sqrt{\frac{\omega}{2 a}} x} \cos \left(\sqrt{\frac{\omega}{2 a}} x-\omega t\right)
\end{array}
$$

burada; $A_{i}$ ve $A_{i+1}$ sırasıyla toprağın $x_{i}$ ve $x_{i+1}$ derinliklerine ait sıcaklık amplitütü; $\omega=2 \pi / \mathrm{P}=\frac{6.28}{86400 s n} \approx 0.0000727 s n^{-1}$-açısal frekans; $P$-periyot, $s n ; t$-zaman, $s n$ 'dir.

Deneme süresince 0-70 $\mathrm{cm}$ toprak profilinin her $10 \mathrm{~cm}$ 'sinde ölçülen toprak sıcaklık değerlerinden hesaplanan ve ısı taşınım (4) eşitliğinde kullanılan amplitüt ve ısısal yayınım katsayıları Çizelge 1'de verilmiştir.

Çizelge 1. Isı taşınım denkleminde kullanılan amplitüt (A) ve ısısal yayınım (a) parametreleri.

\begin{tabular}{lrrrrr}
\hline Toprak derinliği, $\mathrm{cm}$ & $\mathrm{A},{ }^{\circ} \mathrm{C}$ & $\mathrm{a}, \mathrm{cm}^{2} \mathrm{sn}^{-1}$ & Toprak derinliği, $\mathrm{cm}$ & $\mathrm{A},{ }^{\circ} \mathrm{C}$ & $\mathrm{a}, \mathrm{cm}^{2} \mathrm{sn}^{-1}$ \\
\hline 0 & 12.31 & 0 & 40 & 0.64 & $6.65 \times 10^{-3}$ \\
10 & 3.53 & $2.33 \times 10^{-3}$ & 50 & 0.40 & $7.74 \times 10^{-3}$ \\
20 & 1.47 & $3.22 \times 10^{-3}$ & 60 & 0,34 & $1.37 \times 10^{-3}$ \\
30 & 0.90 & $4.78 \times 10^{-3}$ & 70 & 0,21 & $0.16 \times 10^{-3}$ \\
\hline
\end{tabular}


Deneme alanında 0-70 cm toprak profilinin her $10 \mathrm{~cm}$ 'sinde ölçülen toprak sıcaklıkları kullanılarak bu katmanlardaki toprak sıcaklılık değerleri, yüzey toprak sıcaklığı ve derinliğin bir fonksiyonu olarak oluşturulan pedotransfer fonksiyon (ikinci dereceden çoklu regresyon eşitliği) (5) yardımıyla hesaplanmıştır (Ekberli, 2006; Arkhangelskaya, 2014). Pedeotransfer modelin elde edilmesinde MİNİTAB-16 paket programı kullanılmıştır.

Tped $=14,9+0,437 * \mathrm{~T}-0,158 * \mathrm{x}-0,00632 * \mathrm{~T}^{2}+0,000951 * \mathrm{x}^{2}$

burada; T-ölçülen toprak sıcaklık değerlerini, $x$-ölçüm yapılan toprak derinliğidir.

Hata kareler ortalamasının karekökü (HKOK veya RMSE), aşağıdaki eşitlikten hesaplanmıştır:

$$
H K O K=\sqrt{\frac{1}{m} \sum_{i=1}^{n}\left(x_{i}-y_{i}\right)^{2}}
$$

burada, $n$-verilerin sayısı ve $n<30$ ise $m=n-1, n>30$ ise $m=n ; x_{i}$ - ölçülen; $y_{i}$-hesaplanan değerlerdir.

Modelin etkinliği (ME) aşağıdaki eşitlik yardımıyla hesaplanmıștır. Krause ve ark. (2005) tarafından, deneysel hidrolojik modele yönelik bir araștırmada, ME değerlerinin 1 (mükemmel uyum) ile $-\infty$ arasında değiştiği gösterilmiş; ME'nin sıfırdan küçük olması durumunda ise ölçülen ortalama değerin, hesaplanan değerden daha etkin olduğu belirtilmiștir (Krause ve ark., 2005; Willmott ve ark., 2012; Banimahd and Zand-Parsa, 2013; Kumar et al., 2015).

$$
M E=1-\frac{\sum_{i=1}^{n}\left(x_{i}-y_{i}\right)^{2}}{\sum_{i=1}^{n}\left(x_{i}-\bar{x}\right)^{2}}
$$

Burada; $x_{i}$ - ölçülen, $y_{i}$-hesaplanan değerler, $\bar{x}$ ölçülen değerlerin ortalamasıdır.

\section{Bulgular ve Tartışma}

Çalışmanın yürütüldüğü deneme alanına ait toprağın bazı fiziksel ve kimyasal özellikleri Çizelge 2'de verilmiştir. Denme alanında toprağın 0-20 cm katmanı killi (C), 20-60 cm katmanı ise kumlu-tınlı (SL) olup, tuzluluk problemi bulunmamaktadır. Organik madde içeriği ise iyi $(0-20 \mathrm{~cm})$ ile çok az $(20-60 \mathrm{~cm})$ arasında değişmektedir. Toprakta kireç $\left(\mathrm{CaCO}_{3}\right)$ miktarı az olup, ancak 40-50 cm katında çok az birikme gözükmektedir.

Çizelge 2. Deneme alanı toprağına ait bazı fiziksel ve kimyasal özellikler

\begin{tabular}{ccccccc}
\hline Derinlik, cm & Kil, \% & Silt, $\%$ & Kum, \% & OM, \% & $\mathrm{EC}_{25.4^{\circ} \mathrm{C}, \mathrm{dS} \mathrm{m}^{-1}}$ & $\mathrm{CaCO}_{3}, \%$ \\
\hline $0-10$ & 52.58 & 21.78 & 25.64 & 3.55 & 0.35 & 0.34 \\
$10-20$ & 53.75 & 19.10 & 27.15 & 2.39 & 1.07 & 0.19 \\
$20-30$ & 41.60 & 14.92 & 43.48 & 0.77 & 0.40 & 0.16 \\
$30-40$ & 19.58 & 18.65 & 61.77 & 0.33 & 0.20 & 0.18 \\
$40-50$ & 18.37 & 16.12 & 65.51 & 0.16 & 0.25 & 2.96 \\
$50-60$ & 18.68 & 19.17 & 62.15 & 0.18 & 0.25 & 0.18 \\
\hline
\end{tabular}

Deneme alanında 8 - 18 Mayıs 2002 tarihleri arasında 0-70 cm toprak derinliği boyunca her $10 \mathrm{~cm}$ 'de bir ölçülen toprak sıcaklık değerlerine ait tanımlayıcı istatistikler Çizelge 3'te verilmiştir. Toprak profili boyunca günün farklı saatlerinde ölçülen sıcaklık değerlerindeki en fazla değişim toprağın yüzey ve üst katmanlarında gerçekleşmiştir. Toprak derinliği arttıkça sıcaklık değerleri arasındaki varyasyon katsayısı (VK) değerleri de azalma göstermiştir. Bu durum topraktaki asıl ısı kaynağının güneșten gelen radyasyona bağlı olması ve ısınma-soğuma olaylarının toprak yüzeyinde gerçekleşmesi ile açıklanmaktadır (Gülser ve Ekberli, 2004).

Deneme sahasında 8-18 Mayıs 2012 tarihleri arasındaki farklı katmanlardaki toprak sıcaklıkları ısı taşınım denklemi (cosinusoidal harmonik eşitlik) (4) ve pedotransfer fonksiyon (5) kullanılarak hesaplanmış, bu sıcaklık değerlerine ait tanımlayıcı istatistikler Çizelge 4'te verilmiştir. Isı taşınım denklemi (Tcos) ve pedeotransfer fonsiyon (Tped) kullanılarak toprak derinliği boyunca hesaplanan sıcaklık değerlerine ait VK değerleri gerçek sıcaklık ölçüm değerlerine göre (özellikle 10 ve $20 \mathrm{~cm}$ katmanları için) daha düşük hesaplanmıștır (Çizelge 3 ve 4). Tcos ile belirlenen sıcaklıklara ait VK değerlerinde derinlik artışı ile bir azalma olmasına rağmen, Tped ile hesaplanan sıcaklıklara ait VK değerlerinde aksine bir artış belirlenmiştir. 
Genel olarak benzer durum Tcos ve Tped ile hesaplanan sıcaklık değerlerine ait çarpıklık ve basıklık değerlerinde de görülmektedir.

Çizelge 3. Arazide 8-18 Mayıs 2002 tarihleri arasında yapılan toprak sıcaklık ölçümleri $\left({ }^{\circ} \mathrm{C}\right)$.

\begin{tabular}{rcccccrc}
\hline & En düşük, ${ }^{\circ} \mathrm{C}$ & En yüksek, $^{\circ} \mathrm{C}$ & Ortalama, ${ }^{\circ} \mathrm{C}$ & Std. Sapma & VK, $\%$ & Çarpıklık & Basıklık \\
\hline Ty0* & 12,0 & 40,0 & 27,8 & 7,13 & 25,65 & $-0,25$ & $-0,71$ \\
Ty10 & 15,0 & 24,0 & 20,7 & 2,31 & 11,16 & $-0,94$ & 0,45 \\
Ty20 & 15,5 & 20,5 & 18,6 & 1,29 & 6,93 & $-0,86$ & 0,72 \\
Ty30 & 15,0 & 19,00 & 17,7 & 1,05 & 5,93 & $-0,92$ & 0,55 \\
Ty40 & 14,6 & 18,50 & 17,1 & 0,93 & 5,44 & $-0,85$ & 0,58 \\
Ty50 & 14,0 & 18,00 & 16,5 & 0,92 & 5,57 & $-0,49$ & 0,62 \\
Ty60 & 13,8 & 17,50 & 16,0 & 0,86 & 5,37 & $-0,32$ & 0,31 \\
Ty70 & 13,6 & 17,20 & 15,5 & 0,83 & 5,35 & 0,21 & 0,11 \\
\hline
\end{tabular}

*Ty0,.....Ty10: Toprak yüzeyinden itibaren $10 \mathrm{~cm}$ aralıklarla ölçülen sıcaklıklar.

Çizelge 4. Isı taşınım denklemi (Tcos) ve pedotransfer fonksiyon (Tped) ile farklı katmanlar için hesaplanan toprak sıcaklık değerlerine ait tanımlayıcı istatistikler.

\begin{tabular}{|c|c|c|c|c|c|c|c|c|c|c|}
\hline & $\begin{array}{r}\text { En } \\
\text { düşük } \\
\end{array}$ & $\begin{array}{r}\text { En } \\
\text { yüksek }\end{array}$ & Ortalama & $\begin{array}{r}\text { Std. } \\
\text { Sapma }\end{array}$ & VK, \% & Çarpıklık & Basıklık & $\mathrm{R}^{2}$ & HKOK & ME \\
\hline Tcos -10 & 18,5 & 22,3 & 21,0 & 1,14 & 5,42 & $-0,47$ & $-0,99$ & $0,370^{* *}$ & 1,86 & 0,99 \\
\hline Tped-10 & 17,7 & 21,0 & 20,4 & 0,78 & 3,82 & $-1,86$ & 4,21 & $0,514^{* *}$ & 1,90 & 0,79 \\
\hline Tcos-20 & 17,1 & 19,4 & 18,5 & 0,85 & 4,57 & $-0,78$ & $-1,05$ & $0,245^{* *}$ & 1,14 & 0,56 \\
\hline Tped-20 & 16,5 & 19,7 & 19,1 & 0,76 & 4,00 & $-1,81$ & 3,86 & $0,412^{* *}$ & 1,12 & 0,58 \\
\hline Tcos-30 & 16,5 & 18,2 & 17,4 & 0,62 & 3,59 & $-0,32$ & $-1,42$ & 0,011 & 1,21 & $-0,23$ \\
\hline Tped-30 & 15,3 & 18,6 & 18,0 & 0,78 & 4,33 & $-1,86$ & 4,21 & $0,484^{* *}$ & 0,80 & 0,47 \\
\hline Tcos -40 & 16,2 & 17,5 & 16,8 & 0,47 & 2,77 & 0,08 & $-1,37$ & $-0,062$ & 1,17 & $-0,41$ \\
\hline Tped-40 & 14,4 & 17,7 & 17,1 & 0,76 & 4,48 & $-1,92$ & 4,48 & $0,523^{* *}$ & 0,65 & 0,56 \\
\hline Tcos-50 & 16,1 & 16,8 & 16,4 & 0,26 & 1,57 & 0,56 & $-1,06$ & $-0,210^{*}$ & 1,07 & 0,38 \\
\hline Tped-50 & 13,7 & 16,9 & 16,3 & 0,76 & 4,67 & $-1,87$ & 4,22 & $0,490^{* *}$ & 0,69 & 0,74 \\
\hline Tcos -60 & 15,7 & 16,3 & 15,9 & 0,20 & 1,26 & 0,70 & $-0,95$ & $-0,256^{* *}$ & 0,98 & 0,65 \\
\hline Tped-60 & 13,2 & 16,4 & 15,8 & 0,77 & 4,84 & $-1,80$ & 3,88 & $0,500^{* *}$ & 0,67 & 0,84 \\
\hline Tcos-70 & 15,3 & 15,6 & 15,4 & 0,09 & 0,57 & 1,02 & 0,24 & $-0,331^{* *}$ & 0,89 & 0,83 \\
\hline Tped-70 & 12,8 & 16,1 & 15,5 & 0,76 & 4,93 & $-1,94$ & 4,54 & $0,370^{* *}$ & 0,71 & 0,89 \\
\hline Tcos Genel & 15,3 & 22,3 & 17,3 & 1,89 & 10,92 & 1,16 & 0,52 & $0,672^{* *}$ & 1,20 & 0,66 \\
\hline Tped Genel & 12,8 & 21,0 & 17,4 & 1,84 & 10,57 & 0,26 & $-0,64$ & $0,766^{* *}$ & 0,99 & 0,77 \\
\hline
\end{tabular}

Pedotransfer fonksiyondan hesaplanan (Tped) sıcaklık değerleri, ısı akış denkleminin çözümünden (Tcos) hesaplanan sıcaklık değerleri ile karşılaştırıldığında toprak profili boyunca ölçülen toprak sıcaklık değerleriyle daha yüksek $\mathrm{R}^{2}$ değerleri vermiştir (Çizelge 4, Şekil 1). Yüzey toprak katmanında $(10 \mathrm{~cm})$ ölçülen sıcaklık değerleri dikkate alındığında, Tcos ile hesaplanan sıcaklık değerlerinin daha yakın sonuçlar verdiği, Tped ile hesaplanan sıcaklık değerlerinin ise genelde daha düşük değerlerde tahmin edildiği görülmektedir (Şekil 1 ve 2). Bu durum Tcos için hesaplanan HKOK değerinin $(1,86)$ sadece yüzey katmanında $(10 \mathrm{~cm})$ Tped için hesaplanan HKOK değerinden $(1,90)$ düşük bulunması ve Tcos-10 da ölçülen ME değerinin $(0,99)$ 1'e çok yakın olmasından da anlaşılmaktadır (Çizelge 4). Alt toprak katmanlarında ise Tcos ile hesaplanan sıcaklık değerlerinin ölçülen değerlerden daha yüksek olduğu, Tped ile hesaplanan sıcaklık değerlerinin ise ölçülen değerlere daha yakın sonuçlar verdiği görülmektedir (Şekil 1). Alt toprak katmanlarında Tcos sıcaklık değerleri ile karşılaştırıldığında Tped için hesaplanan sıcaklıklara ait $\mathrm{R}^{2}$ değerlerinin daha yüksek, HKOK daha düşük, ve ME'nin 1'e daha yakın olması bu durumu açıklamaktadır (Çizelge 4).

Toprak profili boyunca Tped fonksiyonu ile hesaplanan değerler ölçülen sıcaklık değerleri ile daha yüksek R2 $\left(0,766^{* *}\right)$, daha küçük HKOK $(0,99)$ ve daha büyük ME $(0,77)$ değeri vermiştir. Zhu ve ark. (2014), MODİS (Orta Çözünürlüklü Görüntüleme Spektroradiometresi) verilerini kullanarak toprak yüzeyinde ısı akışının günlük değişiminin belirlenmesinde bir boyutlu ısı iletkenlik denkleminin çözümüne dayanan matematiksel modelden faydalanmış, farklı iki bölgede 432 saatlik bir süre boyunca hesaplanan ve ölçülen yüzey sıcaklık değerleri arasında önemli düzeyde ilişki $\left(\mathrm{R}^{2}=0.984\right.$ ve $\left.\mathrm{R}^{2}=0.986\right)$ belirlemişlerdir. 


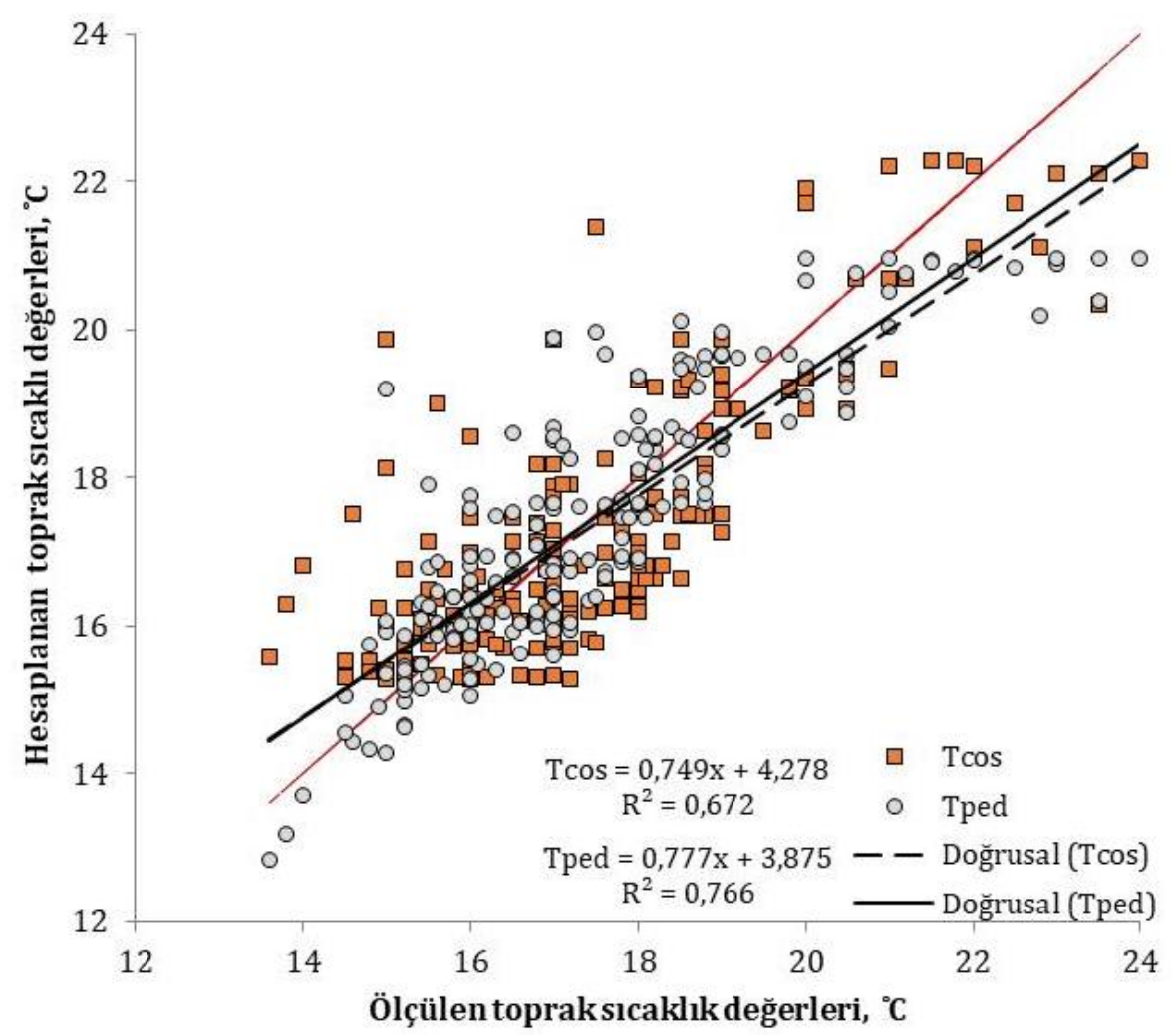

Şekil 1. Ölçülen toprak sıcaklık değerleri ile ısı akış denkleminin çözümünden (Tcos) ve pedotransfer fonksiyondan hesaplanan (Tped) sıcaklık değerleri arasındaki ilişkiler.

Farklı yöntemlerle hesaplanan toprak sıcaklık değerlerinin karşılaștırılmasına örnek oluşturması amacıyla 10 Mayıs tarihinde günün farklı saatlerinde $(8: 45,12: 00,16: 00$ ve 19:00) ölçülen toprak sicaklık değerlerinin, Tcos ve Tped eşitlikleri ile hesaplanan sıcaklık değerleri ile yapılan karşılaştırmaları Şekil 2, 3 ve 4'te verilmiştir. Yüzey katmanlarında (10 ve $20 \mathrm{~cm}$ gibi) gün içinde ölçülen sıcaklık değerlerinin daha geniş bir salınım aralığı göstermesine rağmen (Şekil 2), alt katmanlardaki sıcaklık değerlerinin daha düşük salınım aralığına sahip olduğu görülmektedir (Şekil 3). Gülser ve Ekberli (2004) yaptıkları çalışmada yüzey toprak katmanlarında $(<30 \mathrm{~cm})$ sıcaklık değerlerinin gün içinde fazla değişkenlik göstermesine rağmen, daha derin katmanlarda sıcaklık değişimimin daha az olduğunu ve $50 \mathrm{~cm}$ katmanında ortalamaya yakın hemen hemen sabit sıcaklık değerlerine ulaşıldığını bildirmişlerdir.

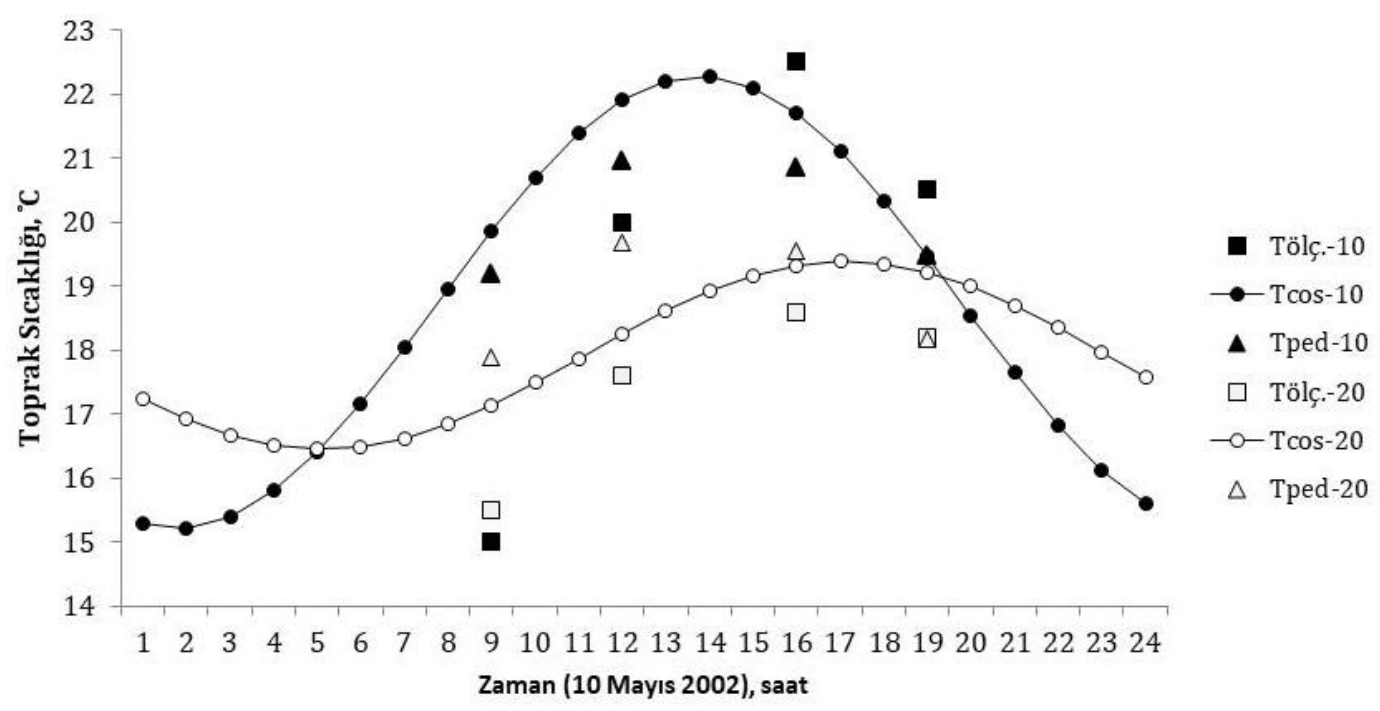

Şekil 2. Toprağın 10 ve $20 \mathrm{~cm}$ katmanlarında örnek olarak günlük ölçülen sıcaklık değerlerinin ısı akış denkleminin çözümünden (Tcos) ve pedotransfer fonksiyondan hesaplanan (Tped) sıcaklık değerleriyle karşılaştırılması. 


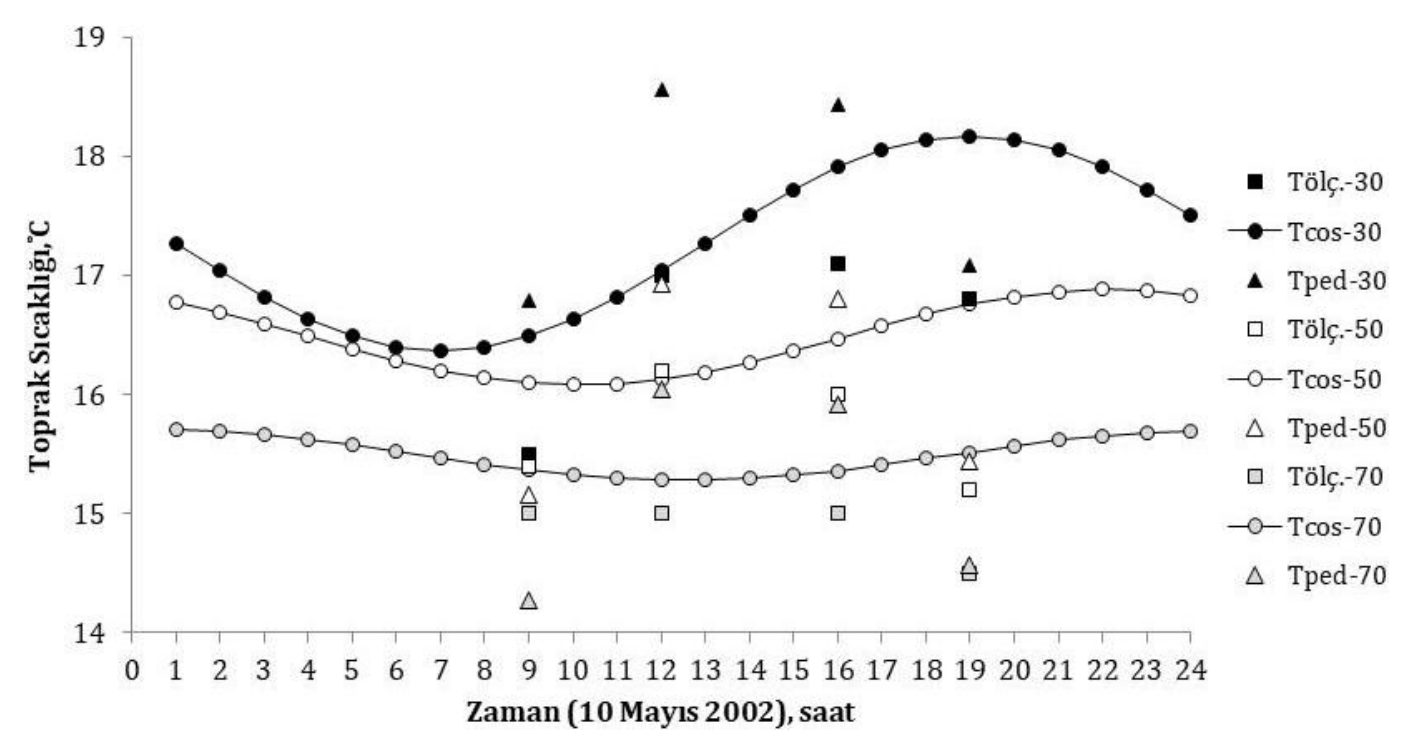

Şekil 3. Toprağın 30, 50 ve 70 cm katmanlarında örnek olarak günlük ölçülen sıcaklık değerlerinin ısı akış d enkleminin çözümünden (Tcos) ve pedotransfer fonksiyondan hesaplanan (Tped) sıcaklık değerleriyle karşılaştırılması.

Günün erken saatlerinde (8:45) yüzey katmanlarda $(<30 \mathrm{~cm})$ ölçülen toprak sıcaklık değerlerinin alt katmanlardaki sıcaklık değerlerinden daha düşük olduğu, hem Tcos, hem de Tped fonksiyonları ile hesaplanan sıcaklık değerlerinin yüzey katman sıcaklıklarını iyi yansıtmadıkları görülmektedir (Şekil 4). Sabah ile öğlen saatleri arasında toprak yüzey katmanlarında gerçekleşen ani sıcaklık değişimlerinin, toprağın alt katmanlarındaki sıcaklık değişimlerinden daha hızlı olduğu ve ısı taşınım denklemleriyle yapılan hesaplamalarda tam olarak yansitılamadığı bildirilmektedir (Gülser ve Ekberli, 2004). Pedotransfer fonksiyonun oluşturulduğu toprak derinliğine ait sınır aralığında, yüzey toprak sıcaklığı kullanılarak herhangi bir derinlikteki toprak sıcaklığı tahmin edilebilmektedir (Şekil 4).
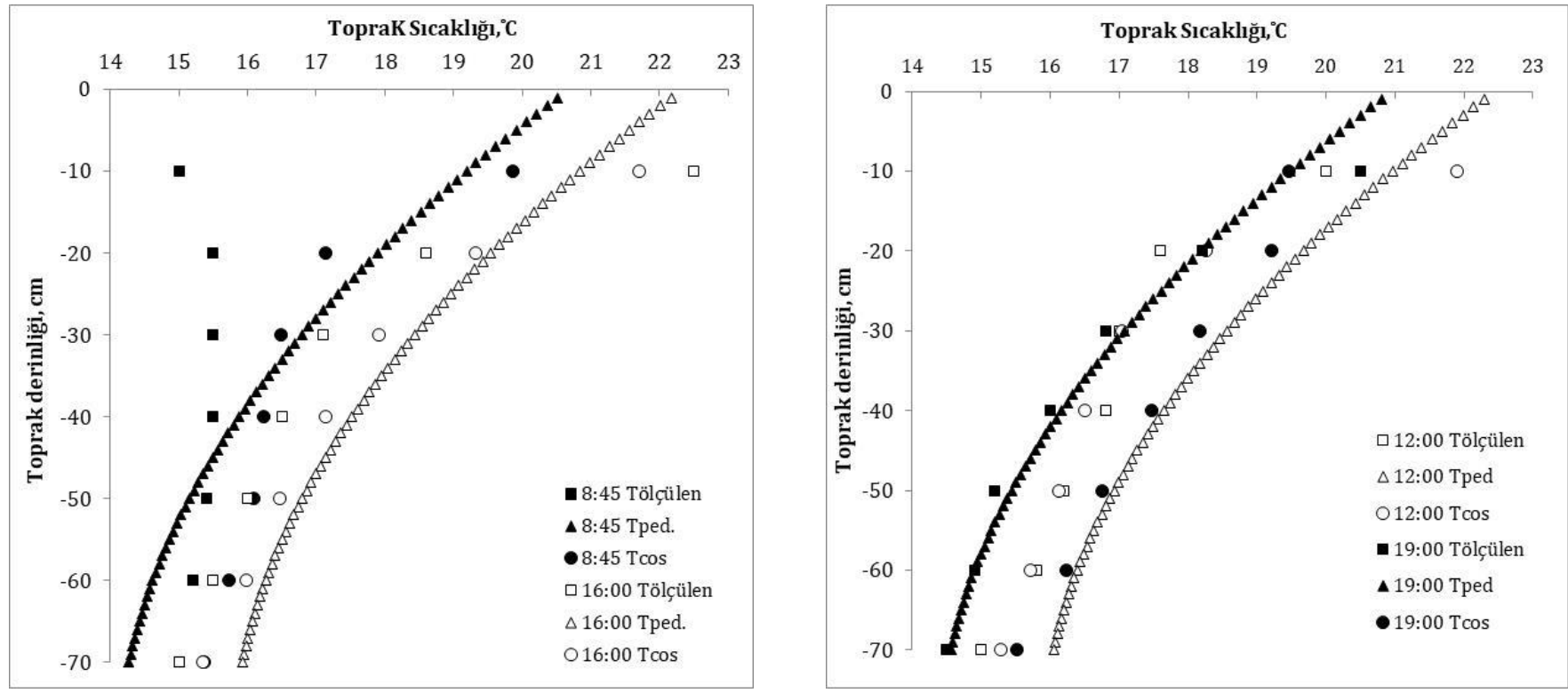

Şekil 4. Toprak profili boyunca örnek olarak günlük ölçülen sıcaklık değerlerinin ısı akış denkleminin çözümünden (Tcos) ve pedotransfer fonksiyondan hesaplanan (Tped) sıcaklık değerleriyle karşılaştırılması.

\section{Sonuç}

Toprağın yüzey ve yüzeye yakın katmanları içi ölçülen toprak sıcaklık değerleri, toprağın daha derin katmanları için ölçülen değerler ile karşılaştırıldığında gün içerisinde daha büyük farklılıklar ve salınımlar göstermektedir. Bu durum topraktaki ısınma ve soğuma olaylarının genelde toprak yüzeyine ulaşan radyasyon ve atmosfer olaylarının etkisinde bulunmasından kaynaklanmaktadır. Toprağın $10 \mathrm{~m}$ yüzey 
katmanında ölçülen sıcaklık değerleri ısı taşınım denkleminin çözümüyle elde edilen (Tcos) eşitlikle hesaplanan değerler ile daha iyi ifade edilmiştir. Toprak derinliği boyunca deneysel olarak ölçülen toprak sıcaklık değerleri genel olarak ikinci dereceden yüzey toprak sıcaklığı ve toprak derinliğinin bir fonksiyonu olarak verilen sınır koşullarında elde edilen pedotransfer fonksiyonla (Tped) hesaplanan sıcaklık değerleri ile daha yüksek ilişki göstermişlerdir. Verilen sınır değerleri için oluşturulan Tped foksiyonu ile yüzey toprak sıcaklık değerleri yardımıyla toprağın herhangi bir derinliğindeki sıcaklık değerinin tahmin edilebileceği anlaşılmaktadır. Pedotransfer fonksiyonla toprak derinliğine bağlı olarak sıcaklığın tahmin edilmesinin ısı taşınım denklemine göre en büyük avantajı, Tped fonksiyonunun oluşturulduğu toprak derinliği aralığındaki herhangi bir derinlikte toprak sıcaklığının tahmin edilebilmesidir. Isı taşınım denklemiyle toprağın farklı derinliklerinde sıcaklığın tahmin edilebilmesi için bu derinliklerdeki ortalama toprak sıcaklığının, amplitütün ve ısısal yayınım katsayılarının hesaplanması gerekmektedir. Toprak sıcaklığının tahmin edilmesi bitki kök bölgesindeki biyolojik ve kimyasal süreçlerin sürdürülebilir yönetimi ve verimlilik açısından önemlidir. Yüzey toprak sıcaklığının yanı sıra diğer meteorolojik verilerinde kullanıldığı pedotransfer fonksiyonların farklı toprak özellikleri ve sıcaklık değerlerini yansıtan sınır değerleri için geliştirilmesi, farklı toprak derinliklerindeki sıcaklık tahmin değerlerinin güvenilirliğini ve hassasiyetini de artıracaktır.

\section{Kaynaklar}

Arkhangelskaya TA, 2014. Diversity of thermal conditions within the paleocryogenic soil complexes of the East European Plain: The discussion of key factors and mathematical modeling. Geoderma, 213: 608-616.

Banimahd SA, Zand-Parsa Sh, 2013. Simulation of evaporation, coupled liquid water, water vapor and heat transport through the soil medium. Agricultural Water Management, 130: 168-177.

Bouma J, 1989. Using soil surve data for quantitative land evaluation. Advances Soil Science, 9: 177-213.

Bouma J, van Lanen HAJ, 1987. Transfer functions and threshold values: from soil characteristics to land qualities. In: Quantified Land Evaluation, Proceedings of a workshop. ISSS/SSSA, Washington, D.C. ITC Publ. Enschede, the Netherlands, pp. 106-110.

Candemir F, Gülser C, 2012. Influencing Factors and Prediction of Hydraulic Conductivity in Fine Textured-Alkaline Soils. Arid Land Research Management, 26:15-31.

Chen J, Saunders S, Crow T, Naiman, R, Brosofske K, Mroz G, Brookshire B, Franklin J, 1999. Microclimate in forest ecosystem and landscape ecology. BioScience, 49: 288-297.

Cho B, Park D, Kim J, Hamasaki H, 2017. Study on the heat-moisture transfer in concrete under real environment. Construction and Building Materials, 132: 124-129.

Demiralay İ, 1993. Toprak fiziksel analiz yöntemleri. Atatürk Üniversitesi Ziraat Fakültesi Yayınları, Erzurum, 111-120.

Donatelli M, Wösten JHM, Belocchi G, 2004. Methods to evaluate pedotransfer functions. Developments in Soil Science, 30: 357-411.

Dong J, Steele-Dunne, SC, Judge J, van de Giesen, N, 2015. Aparticle batch smoother for soil moisture estimation using soil temperature observations. Advances in Water Resources, 83: 111-122.

Ekberli I, 2006. Determination of initial unconditional solution of heat conductivity equation for evaluation of temperature variance in finite soil layer. Journal of Applied Sciences, 6(7): 1520-1526.

Ekberli İ, Dengiz 0, 2017. Bazalt ana materyali ve farklı topografik pozisyonlar üzerinde oluşmuş toprakların bazı topografik ve fiziko- kimyasal özellikleri arasındaki doğrusal regresyon modellerinin belirlenmesi. Toprak $\mathrm{Su}$ Dergisi 6 (1): 15-27.

Ekberli İ, Gülser C, 2014. Estımatıon of soil temperature by heat conductıvity equatıon. Vestnik Bashkir State Agrarian University (Вестник Башкирского Государственного Аграрного Университета), 2(30): 12-15.

Ekberli İ, Gülser C, 2015. İki boyutlu isi iletkenliği denklemine bağlı olarak toprak sıcaklığının matematiksel modellenmesi. Anadolu Tarim Bilimleri Dergisi, 30(3): 287-291.

Ekberli İ, Gülser C, Mamedov A, 2015. Toprakta bir boyutlu isı iletkenlik denkleminin incelenmesinde benzerlik teorisinin uygulanması. Süleyman Demirel Üniversitesi Ziraat Fakültesi Dergisi, 10(2): 69-79

Ekberli İ, Gülser C, Özdemir N, 2017. Farklı toprak derinliklerindeki sıcaklığın tahmininde parabolik fonksiyonun kullanımı. Toprak Bilimi ve Bitki Besleme Dergisi, 5(1): 34- 38.

Evrendilek F, Karakaya N, Gungor K, Aslan G, 2012. Satellite-based and mesoscale regression modeling of monthly air and soil temperatures over complex terrain in Turkey. Expert Systems with Applications, 39: 2059-2066.

Ghanbarian B, Taslimitehrani V, Pachepsky YA, 2017. Accuracy of sample dimension-dependent pedotransfer functions in estimation of soil saturated hydraulic conductivity. Catena, 149: 374-380.

Gülser C, 2004. Tarla kapasitesi ve devamlı solma noktasının toprakların fiziksel ve kimyasal özellikleri ile ilişkili pedotransfer eşitliklerle belirlenmesi. Ondokuz Mayıs Üniversitesi Ziraat Fakültesi Dergisi, 19(3): 19-23.

Gülser C, Ekberli I, 2004. A Comparison of estimated and measured diurnal soil temperature through a clay soil depth. Journal of Applied Science 4(3), 418-423.

Gülser C, Candemir F, 2006. Ondokuz Mayıs Üniversitesi Kurupelit kampüs topraklarının bazı mekaniksel özellikleri ve işlenebilirlikleri. Ondokuz Mayıs Üniversitesi Ziraat Fakültesi Dergisi, 21 (2): 213-217. 
Gülser C, Candemir F, İç S, Demir Z, 2007. Pedotransfer modellerle ince bünyeli topraklarda doygun hidrolik iletkenliğin tahmini. V. Ulusal Hidroloji Kongresi. Orta Doğu Teknik Üniversitesi. Ankara. 5-7 Eylül 2007, s. 563-569.

Gülser C, Ekberli İ, Mamedov A, Özdemir N, 2018. Faz değișimine bağlı olarak ısı iletkenliği denkleminin incelenmesi ve toprak neminin ısısal yayınıma etkisi. Anadolu Tarım Bilimleri Dergisi, 33(3): 261-269.

Haverd V, Cuntz M, Leuning R, Keith H, 2007. Air and biomass heat storage fluxes in a forest canopy: Calculation within a soil vegetation atmosphere transfer model. Agricultural and Forest Meteorology, 147: 125-139.

Hızalan E, Ünal H, 1966. Toprakta önemli kimyasal analizler. Ankara Üniversitesi Ziraat Fakültesi Yayınları, 278s.

Hu G, Zhao L, Wu X, Li R, Wu T, Xie C, Qiao Y, Shi J, Li W, Cheng G, 2016. New Fourier-series-based analytical solution to the conduction-convection equation to calculate soil temperature, determine soil thermal properties, or estimate water flux. International Journal of Heat and Mass Transfer, 95: 815-823.

Ji XB, Kang ES, Zhao WZ, Zhang ZH, Jin BW, 2009. Simulation of heat and water transfer in a surface irrigated, cropped sandy soil. Agricultural Water Management, 96: 1010-1020.

Kacar B, 1994. Bitki ve toprağın kimyasal analizleri:III. Ankara Üniversitesi Ziraat Fakültesi Eğitim, Araştırma ve Geliștirme Vakfı Yayınları. No:3, 89-98.

Kaltreider C, Krarti M, McCartney J, 2015. Heat transfer analysis of thermo-active foundations. Energy and Buildings, 86: 492-501.

Krause P, Boyle DP, Base FB, 2005. Comparison of different efficiency criteria for hydrological model assessment. Advances in Geosciences, 5: 89-97.

Kumar P, Sarangi A, Singh DK, Parihar SS, Sahoo RN, 2015. Simulation of salt dynamics in the root zone and yield of wheat cropunder irrigated saline regimes using SWAP model. Agricultural Water Management, 148: 72-83.

Merlin O, Olivera-Guerra L, Hssaine BA, Amazirh A, Rafi, Z, Ezzahar J, Gentine P, Khabba S, Gascoin S, Er-Raki S, 2018. A phenomenological model of soil evaporative efficiency using surface soil moisture and temperature data. Agricultural and Forest Meteorology, 256-257: 501-515.

Munoz-Criollo JJ, Cleall PJ, Rees SW, 2014. Analysis of inter-seasonal heat fluxes in soils. Energy Procedia, 57: 23152323.

Pachepsky YA, Rawls WJ, 2003. Soil structure and pedotransfer functions. European Journal of Soil Science, 54: 443-452.

Pachepsky YA, Rawls WJ, Lin HS, 2006. Hydropedology and pedotransfer functions. Geoderma, 131: 308-3016.

Shao C, Li L, Dong G, Chen J, 2014. Spatial variation of net radiation and its contribution to energy balance closures in grassland ecosystems. Ecological Processes, 3: 7, 1-11.

Singh VK, Singh BP, Kisi O, Kushwaha DP, 2018. Spatial and multi-depth temporal soil temperature assessment by assimilating satellite imagery, artificial intelligence and regression based models in arid area. Computers and Electronics in Agriculture, 150: 205-219.

Sterling AT, Jackson RD, 1986. Temperature. In: Klute, A. (Ed.), Methods of Soil Analysis

Part 1. Physical and Mineralogical Methods. Agronomy Monograph No. 9, ASA, SSSA, Madison WI.

Xing, L, Li, L, Gong, J, Ren, C, Liu, J, Chen, H, 2018. Daily soil temperatures predictions for various climates in United States using data-driven model. Energy, 160: 430-440.

Xu X, Sun C, Neng F, Fu J, Huang G, 2018. AHC: An integrated numerical model for simulating agroecosystem processes-Model description and application. Ecological Modelling, 390: 23-39.

Wang Z-H, Bou-Zeid E, 2012. A novel approach for the estimation of soil ground heat flux. Agricultural and Forest Meteorology, 154-155: 214- 221.

Willmott CJ, Robeson SM, Matsuura K, 2012. Short Communication. A refined index of model performance. International Journal of Climatology, 32: 2088-2094.

Yan Q, Dong F, Lou G, Yang F, Lu J, Li F, Zhang J, Li J, Duan Z, 2018. Alternate row mulching optimizes soil temperature and water conditions and improves wheat yield in dryland farming. Journal of Integrative Agriculture, 17(11): 2558-2569.

Yener D, Ozgener O, Ozgener L, 2017. Prediction of soil temperatures for shallow geothermal applications in Turkey. Renewable and Sustainable Energy Reviews, 70: 71-77.

Zhu W, Wu B, Yan N, Feng X, Xing Q, 2014. A method to estimate diurnal surface soil heat flux from MODIS data for a sparse vegetation and bare soil. Journal of Hydrology, 511: 139-150. 